\title{
Strategies to optimize treatment adherence in adolescent patients with cystic fibrosis
}

This article was published in the following Dove Press journal:

Adolescent Health, Medicine and Therapeutics

21 October 2016

Number of times this article has been viewed

\section{Lara C Bishay \\ Gregory S Sawicki}

Division of Respiratory Diseases, Boston Children's Hospital, Boston, MA, USA
Correspondence: Lara C Bishay Boston Children's Hospital, 300 Longwood Avenue, Boston, MA 02II5, USA

Tel +I 6173551900

Fax + I 6177300084

Email lara.bishay@childrens.harvard.edu

\begin{abstract}
While development of new treatments for cystic fibrosis (CF) has led to a significant improvement in survival age, routine daily treatment for $\mathrm{CF}$ is complex, burdensome, and time intensive. Adolescence is a period of decline in pulmonary function in $\mathrm{CF}$, and is also a time when adherence to prescribed treatment plans for $\mathrm{CF}$ tends to decrease. Challenges to adherence in adolescents with CF include decreased parental involvement, time management and significant treatment burden, and adolescent perceptions of the necessity and value of the treatments prescribed. Studies of interventions to improve adherence are limited and focus on education, without significant evidence of success. Smaller studies on behavioral techniques do not focus on adolescents. Other challenges for improving adherence in adolescents with $\mathrm{CF}$ include infection control practices limiting in-person interactions. This review focuses on the existing evidence base on adherence intervention in adolescents with CF. Future directions for efforts to optimize treatment adherence in adolescents with $\mathrm{CF}$ include reducing treatment burden, developing patient-driven technology to improve tracking, communication, and online support, and rethinking the CF health services model to include assessment of individualized adherence barriers.
\end{abstract}

Keywords: compliance, adolescence, medication, self management, intervention

\section{Overview of cystic fibrosis and treatments}

Cystic fibrosis (CF) is one of the most common life-limiting genetic diseases among Caucasians, affecting over 30,000 people in the US and more than 70,000 people worldwide. ${ }^{1-5}$ Dysfunction in the CF transmembrane conductance regulator (CFTR) protein leads to altered or absent epithelial anion conductance and transport, resulting in thicker secretions, increased inflammation, and impaired mucosal defense. Consequently, CF has multisystem effects and complications, primarily characterized by pulmonary and digestive dysfunction including chronic sinopulmonary infections, progressive respiratory failure, growth deficits, pancreatic insufficiency, hepatic failure, male infertility, and CF-related diabetes. ${ }^{6,7}$

An arsenal of symptomatic treatments and a multitude of prophylactic daily regimens have fortunately extended the median predicted survival age from young childhood to over 40 years in $2013 .{ }^{8}$ While overall survival and function has improved with the development of new treatments, high adherence is often necessary in order for them to be clinically effective. ${ }^{9-11}$

Treatments for CF fall into multiple categories. These include pancreatic enzyme replacement, fat-soluble vitamin replacement, high-caloric density diets, inhaled 
treatments such as mucolytics, bronchodilators, antibiotics, and corticosteroids, chest physiotherapy and airway clearance, exercise, oral antibiotics, insulin for CF-related

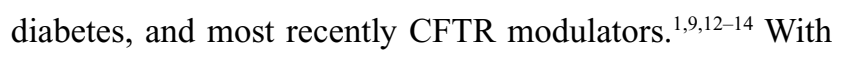
the exception of intravenous antibiotics which are most often used for acute exacerbations, most patients are on a combination of many of the mentioned treatments daily. The treatment regimen for $\mathrm{CF}$ is complex, with many people with $\mathrm{CF}$ reporting significant time burdens associated with daily treatments. ${ }^{9}$ While CF patients' mean pulmonary function measured by forced expiratory volume in 1 second (FEV1) over the past 30 years has on average increased significantly, it continues to decline with age ${ }^{8}$ Furthermore, epidemiologic data suggest that the steepest decline in FEV1 appears to be during adolescent ages 13-21, the adolescent years. ${ }^{8}$ This appears to coincide with a period of greater challenges with adherence to daily treatments. This decline could potentially be explained by the fact that reference equations used to calculate lung function in adults are different from those used in children. ${ }^{15}$ However, the reference equations are changed at the age 18; therefore, this would not explain why lung function decline begins earlier, at the age of 13 , when reference equations are the same.

In determining the appropriate strategies to optimize adherence to prescribed regimens for adolescents with $\mathrm{CF}$, it is important to first review the evidence for declining adherence in adolescents, as well as the barriers to adherence. In order to fully appreciate the context of these issues, it is also important to acknowledge the challenges with measuring adherence as well as review known strategies and their studies to date. The goal of this review is to provide an overview of the mentioned issues and propose areas for further research and intervention development.

\section{Adherence to routine CF treatments: evidence of decline in adolescence}

Adherence to routine CF treatment regimens is associated with improved outcomes and decreased health care costs in acute care. ${ }^{16}$ For example, adherence to nutritional treatments (such as vitamins, diet, enzymes) is associated with higher weight and improved nutritional status, which has in turn been shown in childhood to be associated with improved lung function and in turn longer survival. ${ }^{17}$ Furthermore, airway clearance and chest physiotherapy is associated with maintained lung function and decreased incidence of exacerbations and infection. This is also true of exercise, although its direct effect when used to replace airway clearance is controversial. ${ }^{18-23}$

Evidence suggests that adherence in CF decreases as children get older, particularly in adolescence. ${ }^{10,24,25}$ However, it is important to note that there exist significant difficulties in measuring treatment adherence accurately. ${ }^{26}$ Methods primarily include electronic monitoring devices, pharmacy refill data, administrative claims data, pill counts, and self-reports. Self-report is known to be the least reliable form of measuring adherence when compared to other modalities. ${ }^{26}$ Despite potential inconsistencies and inaccuracies, existing literature in CF generally indicates low overall adherence rates. For example, medication possession ratios (MPRs), calculated as the number of cumulative days of medication dispensed divided by 365 days after the start date of the prescription, can give a general sense of adherence. In 2014, Quittner et al evaluated cumulative MPRs in a sample of 3287 patients with CF from a private claims database and indicated a mean cumulative MPR of $48 \%$, as well as an association between low MPR and higher costs of acute care. ${ }^{16}$ Furthermore, a 5 -year retrospective study by Shakkottai et al comparing number of prescribed refills to the number of actual refills over 1 year indicated that adherence to particular treatments ranged from $46 \%$ to $80 \%$ depending on the medication and the patient age. ${ }^{1}$ Siracusa et al also evaluated adherence to the CFTR modulator ivacaftor in 12 patients using electronic monitoring. ${ }^{27}$ Electronic monitoring data indicated low mean adherence of only $61 \%$, while refill history indicated $84 \%$ and self-report was $100 \%$. This demonstrates the high variability of adherence results based on the measurement method. ${ }^{27}$

Self-report tends to overestimate adherence, and discrepancies in measurement techniques for adherence are demonstrated in the literature. However, studies using multiple techniques to measure adherence and longitudinal studies with internal consistency do provide an overall picture of low adherence in adolescents, which worsens as they grow older. ${ }^{1,26-28}$

\section{Known barriers to treatment adherence in adolescents with CF}

Research to date indicates that lower adherence to prescribed medication regimens may be in part due to difficulties with time management, forgetting, increased complexity of regimens, decreased parental supervision, perceived doubts about the necessity of treatments, stigma and reluctance to disclose CF status, and depression in both patients and their parents. ${ }^{1,5,9,11,24,29-39}$ 
Over the past 2 decades, regimens have increased in complexity with new available treatments causing significant treatment burden. ${ }^{5}$ This has been evaluated both qualitatively and quantitatively. Sawicki et al developed a treatment complexity score from an observational epidemiologic database of 7525 patients. Over 3 years, this score indicated a significant increase in complexity during that time for all ages. In addition, older adult patients were shown to have more complex regimens than younger adult patients. ${ }^{5}$ Questionnaire data from the Project on Adult CF (a longitudinal study of adults with CF) in 204 participants showed that treatment activities required an average of about 2 hours a day., 5,38 Increased treatment burden was associated with using two or more nebulized medications and performing airway clearance treatments for over 30 minutes. Interview data from youth with $\mathrm{CF}$ also revealed that the time burden of treatments, in particular inhaled treatments, posed a significant problem. ${ }^{38}$ Both objective and perceived complexity of daily regimens can also be a barrier to effective treatment adherence. ${ }^{9,38}$

In addition to treatment complexity, the role of the family and parents is paramount in determining adherence. As adolescents move away from regular supervision and developmentally begin to strive for more autonomy, adherence is likely to suffer. Family interactions surrounding CF treatments appear to affect overall adherence. In 2015, Butcher and Nasr recorded and coded in-home respiratory treatments for 15 families. ${ }^{35}$ These families then provided six 24-hour recalls of child medical regimen activities, and electronic airway clearance time was recorded over 3 months to measure medical regimen adherence. Child cooperation was highly associated with positive parental attention, instructions, and avoidance of negative statements. Furthermore, parental presence, positive attention, instructions, and child cooperation during treatments were related to higher respiratory adherence rates. ${ }^{35}$ In addition, studies with multi-method approaches including report scales, refill data, and prescriber prescription data indicated that higher adherence is more likely to occur in children whose parents strongly believe that treatments are necessary. ${ }^{32,34}$ Parental supervision was also found to be associated with improved management by Zindani et al who used electronic monitoring systems. ${ }^{31}$

Another correlate with adherence is the understanding or perception of the treatment necessity. Bucks et al administered a questionnaire to 38 adolescents in 2009 in which nonadherence to chest physiotherapy or airway clearance appeared to be related to perceptions by the patient of treatment's benefits relative to its potential adverse effects. If there were significant doubts about the necessity of a treatment plan, then it was unlikely that the patients would take the prescribed antibiotic. ${ }^{30}$ Younger children with involved parents who strongly believe that treatments are necessary were far more likely to be adherent to their treatment compared to their older counterparts without this type of parental involvement or conviction about the benefit of their treatments. ${ }^{32}$

Finally, both parental and patient depression have also been shown to be associated with worsened adherence to $\mathrm{CF}$ treatment plans. Hilliard et al showed that beliefs about medications significantly mediated this relationship, wherein depressive symptoms were found to be related to beliefs about CF medications..$^{40}$ One study of multiple chronic illnesses, including CF, indicated through an online survey that alcohol and marijuana use is associated with poor adherence as well. ${ }^{41}$

\section{Social isolation/infection control}

Due to colonization with particularly virulent bacteria which can alter a patient's long-term clinical course and lung function, it is now standard of care to recommend that unrelated patients with $\mathrm{CF}$ avoid all contact and meeting. This is to protect patients from cross contamination as the majority of patients are colonized with unique bacterial strains., ${ }^{4,3}, 2$ Therefore, traditional support groups or disease-specific means of social support are curtailed due to infection control. This could conceivably exacerbate patients' feelings of social isolation. Prior to microbiological segregation, socialization between CF patients was encouraged, and interventions which included group workshops were being studied. ${ }^{42}$ So, while support groups and combined group activities are often recommended for patients with chronic illness, CF care guidelines for infection prevention and control preclude that kind of intervention. ${ }^{4}$

\section{Potential strategies to improve adherence}

While numerous studies have defined the issues that appear to hinder adherence as well as those that facilitate it, clear strategies that optimize adherence have had mixed success, and studies are far fewer. Addressing adherence in the clinic encounter is also fraught with challenges. Riekert et al administered a web-based survey of all programs accredited by the US CF Foundation, which showed that only $8 \%$ of respondents actually used any objective measures of adherence in clinic, and only $64 \%$ discussed adherence at each clinic visit. ${ }^{39}$ The most common strategy used to improve adherence was counseling based on education. 
Clear behavioral techniques (such as motivational interviewing [MI] and therapy) are used less regularly. The barriers mentioned were limits in skills, staffing, time, and reimbursement. ${ }^{39}$ This remains an area ripe for future research studies, although the current literature has begun to address this gap. General strategies trialed to improve adherence include education, psychosocial interventions, addressing mental illness and community social support, and online community or text reminders. More recently, there has been some interest in web-based social support and social media, particularly in the setting of inability to have in-person interactions.

\section{Strategies to improve adherence in CF: intervention studies}

Empowering patients with the knowledge of the importance of their regimen and enhancing problem-solving skills is a logical step toward addressing poor treatment adherence in chronic illness. For CF specifically, there are only a few published trials of these types of interventions. In 1996, Cottrell et al conducted a randomized controlled trial of 34 families (mean children's age 13.5 years) where the intervention group received training on principles of $\mathrm{CF}$ including anatomy, physiology, and pharmacology, and selfmanagement strategies for both respiratory and nutritional issues. ${ }^{43}$ Outcomes included weight, knowledge of CF, quality of life, and adherence to treatment as measured through selfreport in treatment diaries 6-8 weeks post-intervention. In general, outcomes were not significantly different between the intervention and control groups except for significant weight gain in the intervention group. However, at baseline, the mean weight in the intervention group was statistically significantly higher than the mean weight in the control group. This was most likely a result of the small sample size. Furthermore, these data were accumulated with three other trials in a Cochrane review, and the statistical significance was lost in this process. ${ }^{12}$ Self-reported adherence to airway clearance did not improve significantly comparing the intervention to the control. The authors concluded that self-management training has a positive effect on self-care in CF. Unfortunately, this study suffered from a short followup time, small sample size, and relying on self-report of adherence which is not ideal. Nevertheless, the feasibility of training in self-management can be obtained from this study.

In 2001, Stapleton et al conducted a randomized controlled trial of 59 children aged 2-11 years where the intervention was based on nutritional information. ${ }^{44}$ The program was called "Go and Grow with CF" and focused on CF-specific nutritional topics (such as enzymes, energy, fat, snacks, and salt) disseminated in written materials, workshops, and weekly activities for 10 weeks completed by children and their caregivers. Questionnaires were used to assess knowledge. Improvement in knowledge was noted in the intervention group immediately post-intervention but not at 1-year follow-up. Weight gain was not a primary outcome. ${ }^{44}$ This study demonstrates the short-term nature of the intervention's impact.

Subsequently in 2006, Downs et al conducted a randomized controlled trial of 62 children (age 11-13 years) and their caregivers of a written home-based educational program named "Airways" which addressed airway clearance and aerosol knowledge. ${ }^{45}$ This was divided into chapters and included written child-friendly activities for the children and their caregivers to complete. Follow-up was longer than the prior study at 12 months, and the groups were reportedly equivalent in gender, age, and FEV1. The intervention group had increased knowledge about airway clearance and improved self-reported adherence to aerosol medications but not in airway clearance performed, and they reported more positive feelings about airway clearance. While this study also suffers from the use of diaries and self-reported adherence, it focuses on younger children compared to Cottrell et al for whom baseline adherence is likely higher than in adolescents. ${ }^{45}$ Nevertheless, this study also indicates that improved knowledge and education might have a mildly positive impact on adherence, although when accumulated with other studies in a meta-analysis, these results were also nonsignificant. ${ }^{12}$

A trial by Watson et al in 2008 evaluated a home-based nutritional behavior intervention called "Eat Well with CF" with 74 patients all older than 16 years. Of note, this intervention was meant to include group workshops as well as home-based educational resources on nutritional issues for CF patients. During recruitment, microbiological segregation for patients colonized with Pseudomonas aeruginosa was introduced, and so, unfortunately, the study could not continue. Results of the study indicated that there were improvements in nutritional knowledge and self-efficacy scores but not in weight. ${ }^{42}$

Given the lack of large, multicenter interventional adherence studies in $\mathrm{CF}$, there is a lack of strong evidence to conclude that any particular intervention leads to significant improvements in patient-centered outcomes such as weight or adherence behaviors, despite improving knowledge. ${ }^{12}$ Ultimately, while these studies show some value to educational interventions, they are clearly necessary yet not sufficient to improve patient outcomes.

In addition to educational interventions, there exist a host of possible psychological and behavioral interventions 
which could improve adherence. However, the data on their effectiveness in adolescents with CF are somewhat limited. Stark et $\mathrm{al}^{46-48}$ conducted multiple smaller studies in the 1990s on improving adherence to nutritional guidelines by providing food diaries and extensive training for caregivers on techniques like praise, ignoring, contingency management, and implementation of a token economy. These studies showed moderate improvement in nutritional intake and status, but focused on younger children under the age of 11 and not adolescents. ${ }^{49-51}$

However, an ongoing study by Quittner et al is testing both a behavioral and a knowledge-based intervention in a 2-year national cluster randomized trial. ${ }^{52,53}$ Eighteen centers in the US are randomized to either standard of care or a behavioral intervention named Comprehensive Adherence Program (CAP) for 1 year. Sites randomized to the standard of care will transition to CAP in the second year. Outcomes will include knowledge scores on health and various treatments, as well as adherence to prescription refills. ${ }^{52,53}$

Regarding behavioral techniques and counseling, the use of MI for medication adherence in chronic illness is growing. MI is a technique that addresses patients' ambivalence toward a particular behavior and uses their own internal motivation to promote behavior change. It is primarily used for substance abuse counseling. While there are no explicit published research trials of $\mathrm{MI}$ in $\mathrm{CF}$, there is a growing interest in its use, and its potential benefit was described by Duff and Latchford in 2010. ${ }^{54}$

Furthermore, the use of technology as a tool to improve adherence in adolescents with CF is a new and emerging field of potential study. This could include online applications for tracking and access to information, online support groups, or home spirometry and the use of telemedicine. Early work by Johnson et al in 2001 indicated that online support groups for teens with $\mathrm{CF}$ were an acceptable medium for communication. ${ }^{11}$ Interestingly, this was prior to the advent of social media. In general, a multitude of online applications for health management have been created and marketed directly to consumers. There is a significant dearth of studies of these applications in chronic illness, but smaller studies in asthma and cancer have shown some promising results. ${ }^{55}$ There is general interest from patients and caregivers in phonebased applications to help with CF coordination of care and improve adherence. ${ }^{56}$ Qualitative work by Hilliard et al on user preferences of a mobile health or mHealth application for adherence in CF indicated that there is interest in application use for $\mathrm{CF}$ for a variety of possible functions. ${ }^{57}$ This was based on interviews with 16 adults with CF. Features that appeared to be preferable included filling prescriptions, access to $\mathrm{CF}$-specific information, and integration with other applications such as calendars, and access to CF care providers. There was hesitation about creating competitions or "games" between patients with CF as patients did not want to compare their health with that of other patients. There were also mixed feelings about interacting with other CF patients online for social support. Universally, participants wanted to limit the need for tedious data entry by the user. ${ }^{57}$

Finally, the idea of patients maintaining their own health data such as their lung function has become more popular recently. Home spirometry has been studied and used for clinical monitoring and early detection of exacerbations in CF with some success. ${ }^{58,59}$ It has not been evaluated as a tool for improving adherence, but there is patient interest in this kind of intervention. ${ }^{57}$

\section{Discussion and future directions}

It is clear that adherence to an increasingly complex CF treatment regimen tends to decline in adolescence. This has a detrimental effect on lung function and potential health outcomes. ${ }^{8}$ Decreased adherence is primarily related to decreased parental involvement, the developmental stage of adolescents seeking independence, time management and significant treatment burden, and perceptions of the necessity and value of the treatments prescribed. ${ }^{25,30,34,37}$ Just as the treatments are complex, so are the reasons for poor adherence. Intervention design for $\mathrm{CF}$ faces a unique challenge as infection control requirements preclude in-person support groups or workshops. ${ }^{2-4}$ Furthermore, measurement of adherence should ideally be triangulated with more than one method of measurement, appreciating that self-report is often the least reliable measure of adherence. ${ }^{26}$

Overall, interventions to improve or optimize adolescent adherence to CF treatment regimens will need to be multipronged and comprehensive. Education, while necessary, is certainly not sufficient. ${ }^{42-44}$ Communication is crucial and allowing patients to understand the importance of their regimens will be important, but understanding how the treatments fit into their lives and their values is also paramount to working on decreasing these barriers. ${ }^{39}$ With this in mind, we have identified three primary future directions for research and service development to optimize adherence in adolescents with CF (Table 1).

First, interventions should explore ways to make therapies and interventions more practical for adolescents through problem solving and negotiating their treatments into their own lives and values. Individual barriers to adherence should be identified when possible through structured assessments and communication with the CF care team. This kind of attention 
Table I Summary of potential strategies to optimize adherence in adolescents with $\mathrm{CF}$

\begin{tabular}{ll}
\hline Intervention & Potential benefits \\
\hline Patient-centered treatment plans & \\
Simplify treatments when possible & Ease treatment burden \\
Structure individual adherence assessments & \\
Shared decision-making & \\
Involve multidisciplinary team and family & \\
$\begin{array}{l}\text { Technology and application development } \\
\text { Create applications for tracking, }\end{array}$ & Increased motivation to \\
information, and communication & improve adherence based \\
& on viewing tracked health \\
& data (PFTs, medication \\
Incorporate self-recorded health into & doses missed, etc) \\
clinical care & Virtual social support \\
Identify social media tools for online & \\
$\begin{array}{l}\text { community support } \\
\text { Improve CF health service model }\end{array}$ & \\
Incorporate adherence discussions & Directly addresses \\
Consider home visits & individualized barriers to \\
Develop community-based initiatives & adherence \\
Address social determinants of health & \\
\hline
\end{tabular}

Abbreviations: CF, cystic fibrosis; PFTs, pulmonary function tests.

and planning requires communication about adherence at each routine outpatient $\mathrm{CF}$ care visit. Interventions should also be tailored to the developmental trajectories of the patient. ${ }^{60}$ These would incorporate peers, multidisciplinary clinician input, parents when appropriate, family or spouses, and ultimately working early with patients to help them practice self-management skills. Ultimately, the goal is to ease some of the treatment burden for the patients and their family. This could include limiting medications or frequency of medications (when medically appropriate) in return for improved adherence. Decreasing treatment burden could also include receiving some treatments at school or during work/commutes, social support from family members, and addressing mental health issues.

This type of clinical encounter draws upon the concept of shared decision-making (SDM), in which the patients take an active role, if desired, in their care plans. The physician initiates an intentional conversation with the patient about his/her disease state, and treatment options and their risks and benefits. ${ }^{61,62}$ This is followed by a negotiated and mutually agreed upon plan that fulfills both the patient's and physician's goals. Data on SDM in the pediatric population is limited, but it has been noted to be of great potential. ${ }^{61}$ Furthermore, in adults with asthma, there is some evidence that adherence to controller medications improves with SDM compared to usual care. ${ }^{62}$ Since barriers to adherence in asthma resemble those in CF, it is likely that SDM will help improve adherence as well. Overall, SDM underlies patient-centered treatment planning.
Outside of $\mathrm{CF}$, adherence to medications for chronic illnesses in adolescents is a challenge in multiple chronic illnesses, and the drivers of poor adherence are similar. These include adolescent development, decreased supervision, regimen burden, and lack of understanding of the importance of the medications. This is very similar to $\mathrm{CF}$, and has been described in sickle cell disease, asthma, mental health disorders, and other more rare chronic illnesses. ${ }^{63-65}$

While randomized trials could provide some information on the effectiveness of increasing the priority of adherence training into the CF care team, this kind of change may also lend itself to quality improvement initiatives, whereby results could potentially be identified more rapidly.

Second, technology development is important as it could potentially help with tracking, communication, access to medical information, and potentially online support with other CF patients. Of note, social media and application design would need to be developed with patient input and thoughtful consideration to potential risks, further burden on the patient, and appropriate catering to the patient's individual needs. Some early work has begun to explore these issues, but further studies such as focus groups, adolescent qualitative interviews, needs assessments, and input into intervention design would increase the chance of successful intervention design. Furthermore, allowing the patients to gather and own their own data, such as through fitness trackers, accelerometers, or home spirometry, is another avenue through which adherence could be addressed and potentially improved, making it an area ripe for further research. Ideally, vigorous randomized trials for these kinds of interventions would provide useful data on their effectiveness.

Third, discussions and interventions to improve adherence often require significant resources and time. It is unfortunate that discussion of adherence is often not reimbursed, given that it is known that improved adherence is associated with reduced morbidity, decreased health costs, and longer survival. ${ }^{16}$ The structure of clinic visits might need to be rethought, and home visits or community-based initiatives may be the key toward empowering patients to take control of their illness and optimize their self-management. Furthermore, it is notable that, despite the presumed negative effects that social factors such as food and housing insecurity would have on a patient's ability to adhere to a complex CF regimen, this possible relationship has not been studied. As health care payment reform starts to allow reimbursement for a wider range of preventative services, systems should be developed for reimbursing adherence discussions, home visits, community-based initiatives, and services that address the social determinants of health. Doing so would ultimately work toward improving outcomes for adolescents with CF. 


\section{Acknowledgment}

Research reported in this publication was supported by the Eunice Kennedy Shriver National Institute of Child Health and Human Development of the National Institutes of Health under Award Number T32HD075727. The content is solely the responsibility of the authors and does not necessarily represent the official views of the National Institutes of Health.

\section{Disclosure}

Dr. Gregory Sawicki has served on advisory boards for Genentech, Novartis, and Vertex Pharmaceuticals and receives research funding from the Cystic Fibrosis Foundation. Dr. Lara Bishay has received unrelated research funding from Vertex Pharmaceuticals. The authors report no other conflicts of interest in this work.

\section{References}

1. Shakkottai A, Kidwell KM, Townsend M, Nasr SZ. A five-year retrospective analysis of adherence in cystic fibrosis. Pediatr Pulmonol. 2015;50(12):1224-1229.

2. Govan JR, Brown PH, Maddison J, et al. Evidence for transmission of Pseudomonas cepacia by social contact in cystic fibrosis. Lancet. 1993;342(8862):15-19.

3. Kalish LA, Waltz DA, Dovey M, et al. Impact of Burkholderia dolosa on lung function and survival in cystic fibrosis. Am J Respir Crit Care Med. 2006;173(4):421-425.

4. Saiman L, Siegel JD, LiPuma JJ, et al. Infection prevention and control guideline for cystic fibrosis: 2013 update. Infect Control Hosp Epidemiol. 2014;35 Suppl 1:S1-S67.

5. Sawicki GS, Ren CL, Konstan MW, Millar SJ, Pasta DJ, Quittner AL; Investigators and Coordinators of the Epidemiologic Study of Cystic Fibrosis Treatment complexity in cystic fibrosis: trends over time and associations with site-specific outcomes. J Cyst Fibros. 2013;12(5):461-467.

6. Stoltz DA, Meyerholz DVM, Welsh MJ. Origins of cystic fibrosis lung disease. N Engl J Med. 2015;372:361-362.

7. Colin AA, Wohl ME. Cystic fibrosis. Pediatr Rev. 1994;15(5):192-200.

8. Preston W. Highlights of the 2014 Patient Registry Data. Cystic Fibrosis Foundation Yearly Publication. 2014. Available from: https:/www.cff. org/Our-Research/CF-Patient-Registry/Highlights-of-the-2014-PatientRegistry-Data/. Accessed October 07,2016.

9. Sawicki GS, Sellers DE, Robinson WM. High treatment burden in adults with cystic fibrosis: challenges to disease self-management. $J$ Cyst Fibros. 2009;8(2):91-96.

10. Eakin MN, Bilderbeck A, Boyle MP, Mogayzel PJ, Riekert KA. Longitudinal association between medication adherence and lung health in people with cystic fibrosis. J Cyst Fibros. 2011;10(4):258-264.

11. Johnson KB, Ravert RD, Everton A. Hopkins teen central: assessment of an internet based support group for children with cystic fibrosis. Pediatrics. 2001;107(2):E24.

12. Savage E, Beirne PV, Ni Chroinin M, Duff A, Fitzgerald T, Farrell D. Self-management education for cystic fibrosis. Cochrane Database Syst Rev. 2011;(7):CD007641.

13. Kettler L, Sawyer S, Winefield H, Greville H. Determinants of adherence in adults with cystic fibrosis. Thorax. 2002;57(5):459-464.

14. Cheng J, Purcell HN, Dimitriou SM, Grossoehme DH. Testing the feasibility and acceptability of a chaplaincy intervention to improving treatment attitudes and self-efficacy of adolescents with cystic fibrosis: a pilot study. J Health Care Chaplain. 2015;21(2):76-90.

15. Kirkby J, Aurora P, Spencer H, Rees S, Sonnappa S, Stocks J. Stitching and switching: the impact of discontinuous lung function reference equations. Eur Respir J. 2012;39(5):1256-1257.
16. Quittner AL, Zhang J, Marynchenko M, et al. Pulmonary medication adherence and health-care use in cystic fibrosis. Chest. 2014;146(1): $142-151$.

17. McPhail GL, Acton JD, Fenchel MC, Amin RS, Seid M. Improvements in lung function outcomes in children with cystic fibrosis are associated with better nutrition, fewer chronic Pseudomonas aeruginosa infections, and dornase alfa use. J Pediatr. 2008;153(6):752-757.

18. Prasad SA, Cerny FJ. Factors that influence adherence to exercise and their effectiveness: application to cystic fibrosis. Pediatr Pulmonol. 2002;34(1):66-72.

19. Kriemler S, Kieser S, Junge S, et al. Effect of supervised training on FEV1 in cystic fibrosis: a randomised controlled trial. J Cyst Fibros. 2013;12(6):714-720.

20. Moorcroft A, Dodd M, Morris J, Webb A. Individualised unsupervised exercise training in adults with cystic fibrosis: a 1 year randomised controlled trial. Thorax. 2004;59(12):1074-1080.

21. Paranjape SM, Barnes LA, Carson KA, von Berg K, Loosen H, Mogayzel PJ Jr. Exercise improves lung function and habitual activity in children with cystic fibrosis. J Cyst Fibros. 2012;11(1):18-23.

22. Schneiderman-Walker J, Pollock SL, Corey M, et al. A randomized controlled trial of a 3-year home exercise program in cystic fibrosis. $J$ Pediatr. 2000;136(3):304-310.

23. Selvadurai HC, Blimkie CJ, Meyers N, Mellis CM, Cooper PJ, Van Asperen PP. Randomized controlled study of in-hospital exercise training programs in children with cystic fibrosis. Pediatr Pulmonol. 2002;33(3):194-200.

24. Arias Llorente RP, Bousoño García C, Díaz Martín JJ. Treatment compliance in children and adults with cystic fibrosis. J Cyst Fibros. 2008;7(5):359-367.

25. Conway SP, Pond MN, Hamnett T, Watson A. Compliance with treatment in adult patients with cystic fibrosis. Thorax. 1996;51(1):29-33.

26. Daniels T, Goodacre L, Sutton C, Pollard K, Conway S, Peckham D. Accurate assessment of adherence: self-report and clinician report vs electronic monitoring of nebulizers. Chest. 2011;140(2):425-432.

27. Siracusa CM, Ryan J, Burns L, et al. Electronic monitoring reveals highly variable adherence patterns in patients prescribed ivacaftor. $J$ Cyst Fibros. 2015;14(5):621-626.

28. Burrows JA, Bunting JP, Masel PJ, Bell SC. Nebulised dornase alpha: adherence in adults with cystic fibrosis. $J$ Cyst Fibros. 2002;1(4):255-259.

29. Modi AC, Lim CS, Yu N, Geller D, Wagner MH, Quittner AL. A multimethod assessment of treatment adherence for children with cystic fibrosis. J Cyst Fibros. 2006;5(3):177-185.

30. Bucks RS, Hawkins K, Skinner TC, Horn S, Seddon P, Horne R. Adherence to treatment in adolescents with cystic fibrosis: the role of illness perceptions and treatment beliefs. J Pediatr Psychol. 2009;34(8): 893-902.

31. Zindani GN, Streetman DD, Streetman DS, Nasr SZ. Adherence to treatment in children and adolescent patients with cystic fibrosis. $J$ Adolesc Heal. 2006;38(1):13-17.

32. Goodfellow NA, Hawwa AF, Reid AJ, Horne R, Shields MD, McElnay JC. Adherence to treatment in children and adolescents with cystic fibrosis: a cross-sectional, multi-method study investigating the influence of beliefs about treatment and parental depressive symptoms. BMC Pulm Med. 2015;15:43.

33. DeLambo KE, Ievers-Landis CE, Drotar D, Quittner AL. Association of observed family relationship quality and problem-solving skills with treatment adherence in older children and adolescents with cystic fibrosis. J Pediatr Psychol. 2004;29(5):343-353.

34. Modi AC, Quittner AL. Barriers to treatment adherence for children with cystic fibrosis and asthma: what gets in the way? J Pediatr Psychol. 2006;31(8):846-858.

35. Butcher JL, Nasr SZ. Direct observation of respiratory treatments in cystic fibrosis: parent-child interactions relate to medical regimen adherence. J Pediatr Psychol. 2015;40(1):8-17.

36. Patterson JM, Wall M, Berge J, Milla C. Gender differences in treatment adherence among youth with cystic fibrosis: development of a new questionnaire. J Cyst Fibros. 2008;7(2):154-164. 
37. Dziuban EJ, Saab-Abazeed L, Chaudhry SR, Streetman DS, Nasr SZ. Identifying barriers to treatment adherence and related attitudinal patterns in adolescents with cystic fibrosis. Pediatr Pulmonol. 2010;45(5):450-458.

38. Sawicki GS, Heller KS, Demars N, Robinson WM. Motivating adherence among adolescents with cystic fibrosis: youth and parent perspectives. Pediatr Pulmonol. 2015;50(2):127-136.

39. Riekert KA, Eakin MN, Bilderback A, Ridge AK, Marshall BC. Opportunities for cystic fibrosis care teams to support treatment adherence. J Cyst Fibros. 2015;14(1):142-148.

40. Hilliard ME, Eakin MN, Borrelli B, Green A, Riekert KA. Medication beliefs mediate between depressive symptoms and medication adherence in cystic fibrosis. Health Psychol. 2015;34(5):496-504.

41. Weitzman ER, Ziemnik RE, Huang Q, Levy S. Alcohol and marijuana use and treatment nonadherence among medically vulnerable youth. Pediatrics. 2015;136(3):450-457.

42. Watson H, Bilton D, Truby H. A randomized controlled trial of a new behavioral home-based nutrition education program, "Eat Well with CF," in adults with cystic fibrosis. J Am Diet Assoc. 2008;108(5): $847-852$.

43. Cottrell CK, Young GA, Creer TL, Holroyd KA, Kotses H. The development and evaluation of a self-management program for cystic fibrosis. Pediatr Asthma Allergy Immunol. 2009;10(3):109-118.

44. Stapleton DR, Gurrin LC, Zubrick SR, Silburn SR, Sherriff JL, Sly PD. The effect of "Go and Grow with CF" on nutrition and pancreatic enzyme knowledge of children with cystic fibrosis. Aust J Nutr Diet. 2001;58(3):164-169.

45. Downs JA, Roberts CM, Blackmore AM, Le Souëf PN, Jenkins SC. Benefits of an education programme on the self-management of aerosol and airway clearance treatments for children with cystic fibrosis. Chron Respir Dis. 2006;3(1):19-27.

46. Stark LJ, Knapp LG, Bowen AM, et al. Increasing calorie consumption in children with cystic fibrosis: replication with 2-year follow-up. J Appl Behav Anal. 1993;26(4):435-450.

47. Stark LJ, Mulvihill MM, Powers SW, et al. Behavioral intervention to improve calorie intake of children with cystic fibrosis: treatment versus wait list control. J Pediatr Gastroenterol Nutr. 1996;22(3):240-253.

48. Stark LJ, Powers SW, Jelalian E, Rape RN, Miller DL. Modifying problematic mealtime interactions of children with cystic fibrosis and their parents via behavioral parent training. J Pediatr Psychol. 1994;19(6):751-768.

49. Goldbeck L, Fidika A, Herle M, Quittner AL. Psychological interventions for individuals with cystic fibrosis and their families. Cochrane Database Syst Rev. 2014;(6):CD003148.

50. Kahana S, Drotar D, Frazier T. Meta-analysis of psychological interventions to promote adherence to treatment in pediatric chronic health conditions. J Pediatr Psychol. 2008;33(6):590-611.

51. Bernard RS, Cohen LL. Increasing adherence to cystic fibrosis treatment: a systematic review of behavioral techniques. Pediatr Pulmonol. 2004;37(1):8-16.
52. Quittner A, Kimberg C, Marciel K, Zhang J, Riekert K. Randomized, controlled trial of a behavioral adherence intervention for adolescents with cystic fibrosis: I change adherence and raise expectations (iCARE). Chest. 2011;140(4_MeetingAbstracts):908A.

53. Quittner AL, Hernández CM, Kroeker LR, et al. WS4.5 Knowledge and skills in managing CF: data from the I Change Adherence and Raise Expectations (iCARE) study. J Cyst Fibros. 2012;11:S10.

54. Duff AJ, Latchford GJ. Motivational interviewing for adherence problems in cystic fibrosis. Pediatr Pulmonol. 2010;45(3):211-220.

55. Majeed-Ariss R, Baildam E, Campbell M, et al. Apps and adolescents: a systematic review of adolescents' use of mobile phone and tablet apps that support personal management of their chronic or long-term physical conditions. J Med Internet Res. 2015;17(12):e287.

56. Marciel KK, Saiman L, Quittell LM, Dawkins K, Quittner AL. Cell phone intervention to improve adherence: cystic fibrosis care team, patient, and parent perspectives. Pediatr Pulmonol. 2010;45(2):157-164.

57. Hilliard ME, Hahn A, Ridge AK, Eakin MN, Riekert KA. User preferences and design recommendations for an mHealth app to promote cystic fibrosis self-management. JMIR MHealth UHealth. 2014;2(4):e44.

58. Tagliente I, Trieste L, Solvoll T, Murgia F, Bella S. Telemonitoring in cystic fibrosis: a 4-year assessment and simulation for the next 6 years. Interact J Med Res. 2016;5(2):e11.

59. Lechtzin N, West N, Allgood S, et al. Rationale and design of a randomized trial of home electronic symptom and lung function monitoring to detect cystic fibrosis pulmonary exacerbations: the early intervention in cystic fibrosis exacerbation (eICE) trial. Contemp Clin Trials. 2013;36(2):460-469.

60. Costello RW, Foster JM, Grigg J, et al; Respiratory Effectiveness Group. The seven stages of man: the role of developmental stage on medication adherence in respiratory diseases. J Allergy Clin Immunol Pract. 2016;4(5):813-820.

61. Rivera-Spoljaric K, Halley M, Wilson SR. Shared clinician-patient decision-making about treatment of pediatric asthma: what do we know and how can we use it? Curr Opin Allergy Clin Immunol. 2014;14(2):161-167.

62. Wilson SR, Strub P, Buist AS, et al; Better Outcomes of Asthma Treatment (BOAT) Study Group. Shared treatment decision making improves adherence and outcomes in poorly controlled asthma. Am J Respir Crit Care Med. 2010;181(6):566-577.

63. Nazareth M, Richards J, Javalkar K, et al. Relating health locus of control to health care use, adherence, and transition readiness among youths with chronic conditions, North Carolina, 2015. Prev Chronic Dis. 2016:13;E93.

64. Smaldone A, Findley S, Bakken S, Matiz L. Study protocol for a randomized controlled trial to assess the feasibility of an open label intervention to improve hydroxyurea adherence in youth with sickle cell. Contemp Clin Trials. 2016;49:134-142.

65. Dean AJ, Walters J, Hall A. A systematic review of interventions to enhance medication adherence in children and adolescents with chronic illness. Arch Dis Child. 2010;95(9):717-723.
Adolescent Health, Medicine and Therapeutics

Publish your work in this journal

Adolescent Health, Medicine and Therapeutics is an international, peer-reviewed, open access journal focusing on health, pathology, and treatment issues specific to the adolescent age group. All aspects of health maintenance, preventative measures and disease treatment interventions are addressed within the journal and practitioners from all disciplines are invited to submit their work as well as healthcare researchers and patient support groups. This journal is included in PubMed. The manuscript management system is completely online and includes a very quick and fair peer-review system. Visit http://www.dovepress.com/testimonials. php to read real quotes from published authors. 